\title{
FERRAMENTAS EDUCACIONAIS BASEADAS EM M-LEARNING: ESTUDO DE CASO NO NÚCLEO DE EDUCAÇÃO À DISTÂNCIA DO SENAI GOIÁS
}

\author{
GOIÂNIA/GO JULHO/2018
}

\author{
Paulo de Sá Filho - IFGoiano - prof.paulo@hotmail.com.br \\ Flávio Pereira Camargo - UFG - camargolitera@gmail.com \\ Marco Carvalho - IFGoiano - marco.carvalho@ifgoiano.edu.br
}

Tipo: Investigação Científica (IC)

Natureza: Relatório Final de Pesquisa

Categoria: Métodos e Tecnologias

Setor Educacional: EDUCAÇÃO MÉDIA E TECNOLÓGICA, EDUCAÇÃO CORPORATIVA

\section{RESUMO}

Na contemporaneidade, a expansão do uso de dispositivos móveis para diversos fins tem possibilitado a inserção desses aparelhos no processo de ensino-aprendizagem. $O$ objetivo deste artigo é apresentar e discutir algumas das principais ferramentas educacionais baseadas no $M$ Learning e as percepções de professores-tutores sobre a Aprendizagem-Móvel a partir de um estudo de caso realizado no Núcleo de Educação à Distância - NIEAD do SESI/SENAI Goiás, para tal estudo utilizou da aplicação de um questionário, com vinte seis questões sendo estas abertas e fechadas. Como, resultado principal, destaca-se a expansão do uso de dispositivos móveis, com isso criando um desenho favorável para aplicação pedagógica desses recursos. Fator que fortalece essa ação de implementação, é que também identificou-se que a maioria dos docente são favoráveis a utilização de recursos digitais baseados em mlearning.

Palavras-chave: M-learnig, Educação à Distância, SESI/SENAI.

\section{AGRADECIMENTOS}

AGRADECEMOS AO AUTOR DA VIDA, POIS NINGUÉM TEM NADA SE DO CÉU NÃO LHE FOR DADO (BÍBLIA JOÃO 3:27). AOS NOSSOS FAMILIARES POR INCENTIVAREM EM TODOS OS MOMENTOS. 


\section{INTRODUÇÃo}

O advento das novas tecnologias em diversos setores da sociedade fazem com que as pessoas fiquem cada vez mais tecnologicamente conectadas, em especial, por meio dos dispositivos móveis. Com isso, as pessoas têm utilizado dispositivos móveis como os smartphones e tablets para diversos fins, desde o lazer até no aprendizado escolar. Dessa maneira, esses dispositivos moveis têm adentrado os espaços escolares e se tornado novos aliados no processo de ensino aprendizagem. Contudo, o uso de dispositivos móveis como ferramenta educacional, ainda é um grande desafio a transpor.

Esse desafio surge, em especial, porque, no ambiente escolar, temos a presença de duas gerações. A primeira geração conhecida como os nativos digitais que, conforme Palfrey e Gasser (apud Santos et. al, 2011) são os nascidos após 1980 e que tem habilidade para usar as tecnologias digitais. E a segunda geração, denominada imigrantes digitais, que são aqueles que não nasceram no mundo digital, mas que, em algum momento da vida, adotou o uso das novas tecnologias (PRENSKY, 2001). A geração dos nativos digitais é composta em grande parte pelos alunos. Já a dos imigrantes digitais pelos professores. Surgindo, com isso, embates sobre a utilização dos dispositivos móveis no processo de ensino aprendizagem. Onde em muitos casos, tem-se optado na proibição do uso em especial de celulares dentro das salas de aulas.

Como forma de contribuir com a superação desse desafio, esta pesquisa tem como objetivo geral analisar as percepções dos professores tutores acerca das ferramentas educacionais baseadas em M-learning utilizadas em cursos a distância de Educação Profissional e Tecnológica do SENAI Goiás. E, como objetivos específicos, descrever as principais ferramentas educacionais baseadas e identificar as percepções dos professores tutores acerca das ferramentas educacionais baseadas em M-learning, utilizadas nos cursos a distância do SENAI Goiás. Respondendo, com isso, a seguinte problemática, quais as percepções dos professores tutores acerca da utilização de ferramentas educacionais baseadas em M-learning em cursos de Educação Profissional e Tecnológica a distância do SENAI Goiás?

\section{REFERENCIAL TEÓRICO}

\subsection{M-learning}

Para Gueddes apud Ferreira et all (2012) o M-Learning (Mobile Learning), ou aprendizagem com mobilidade, é a "aquisição de conhecimento e habilidades por meio 
de tecnologia móvel em qualquer lugar e em qualquer tempo". Já Liu et al vai um pouco além definindo o m-learning como

o processo de adquirir conhecimento e de aprender através das tecnologias móveis, trata-se de uma nova forma de desenvolvimento, que pode ser realizada em qualquer lugar e em qualquer hora, e pode proporcionar redução de custos com a infraestrutura para a empresa (apud Moscardini et all 2013).

Tendo como base essas definições, podemos estabelecer que M-learning é toda a aprendizagem resultante da interação com dispositivos móveis, com ou sem mediação de um professor. Por não haver essa obrigatoriedade, ou seja, de um docente no processo de ensino-aprendizagem, podem surgir com isso, resistências à adoção e aplicação do M-learnig pelos professores. Contudo Moran (2013) diz que a escola precisa entender que uma parte cada vez maior da aprendizagem pode ser feita sem estarmos na sala de aula e sem a supervisão direta do professor. Isso assusta, mas é um processo inevitável. Essa afirmação de inevitabilidade do uso e aplicação da aprendizagem móvel é solidificada e fortalecida quando observamos as pesquisas de posse e uso pessoal de dispositivo móvel, realizadas pelo Instituto Brasileiro de Geografia e Estatística - IBGE.

De acordo com o IBGE (2016)

em 2015 o contingente de pessoas de 10 anos ou mais de idade que tinham telefone móvel celular para uso pessoal era de 139,1 milhões, o que correspondia a $78,3 \%$ da população do País nessa faixa de idade. Em relação a 2005, esse contingente aumentou $147,2 \%$ (82,8 milhões de pessoas).

Esse cenário de expansão se repete com relação ao tablet, que em 16,3\% dos domicílios particulares brasileiros possuem esse dispositivo (IBGE, 2016). Ao olhar para o centro-oeste do Brasil, região onde está localizada o objeto de nosso estudo, temos que $16,2 \%$ domicílios particulares dessa região possuem tablets (IBGE, 2016), seguindo, assim, a média nacional. Já, em relação ao número de pessoas que possuem telefone móvel, o centro-oeste se destaca como a região que apresenta maior proporção de com telefone celular, conforme a figura 1.

Figura 1: Gráfico Percentual de pessoas que tinham telefone móvel celular para uso na população de 10 anos ou mais de idade, por Grandes Regiões - 2005/2015 
Gráfico 29 - Percentual de pessoas que tinham telefone móvel celular para uso pessoal, na população de 10 anos ou mais de idade, por Grandes Regiões - 2005/2015

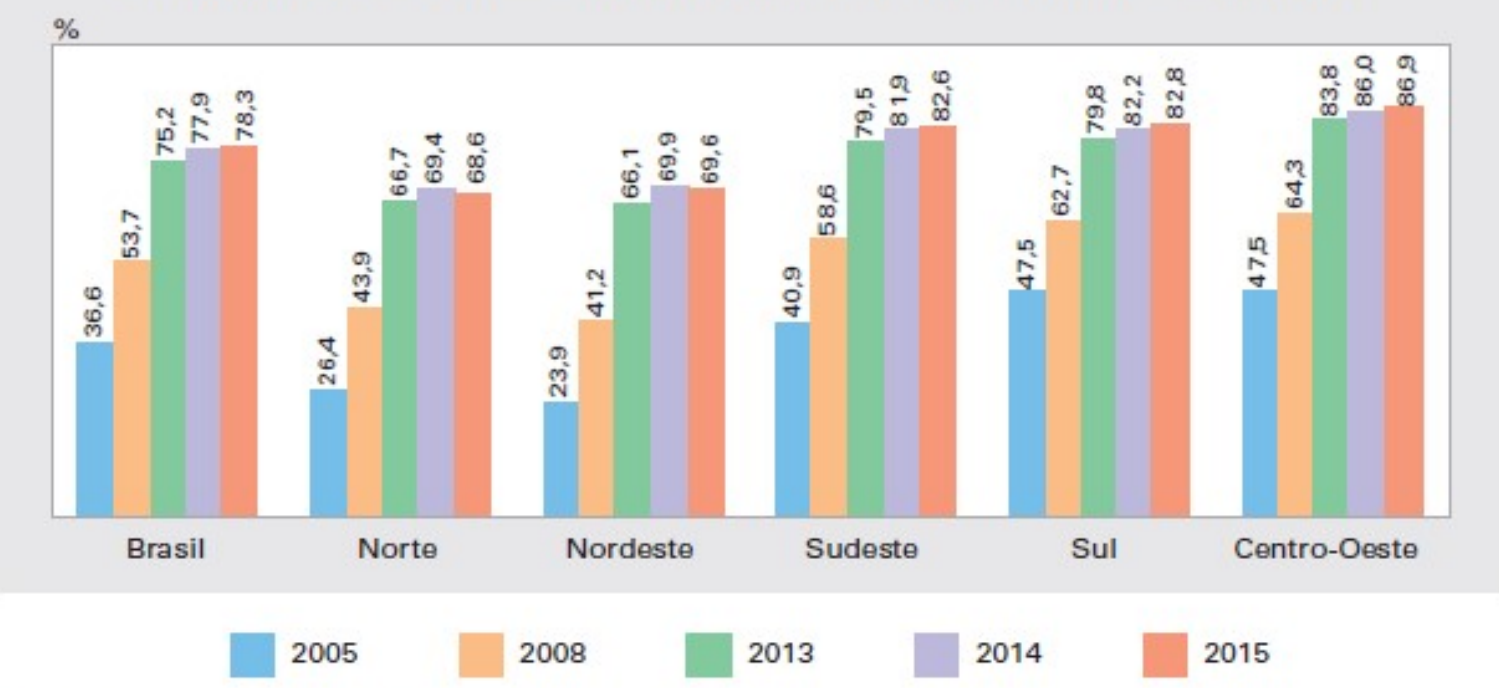

Fonte: IBGE, Diretoria de Pesquisas, Coordenação de Trabalho $\Theta$ Rendimento, Pesquisa Nacional por Amostra de Domicilios 2005/205.

Fonte: IBGE, 2016

Nesse contexto de ampliação do uso de tecnologias móveis, justifica-se desenvolver estudos e pesquisas que busquem compreender o M-learning e descrever ferramentas educacionais baseadas nesse processo de aprendizagem.

\subsection{Ferramentas educacionais baseadas em M-learning}

Os educadores no desejo de inovar as práticas educativas têm revisto sua maneira de atuação no processo de ensino-aprendizagem, buscando e testando novas ferramentas educacionais como suporte e para ir além do uso do quadro verde ou branco, assim atuando de forma inovadora (SEEGGER et al, 2012). Sobre essa perspectiva de busca docente por práticas educativas inovadores, é viável que se conheça exemplos de ferramentas educacionais que os auxiliem nessa procura.

\section{MÉTODO DA PESQUISA}

O delineamento da pesquisa trata-se de um estudo de caso institucional, de cunho documental e bibliográfico. Tem caráter descritivo exploratório e natureza qualitativa e quantitativa. É um estudo de caso, pois estuda indivíduos, no caso tutores que são representativos ao universo pesquisado, como estabelecem (CERVO e BERVIAN, 2002). O seu cunho documental é devido ter-se realizado coleta de dados em arquivos particulares da instituição pesquisada (LAKATOS E MARCONI, 2001), e bibliográfico, por utilizar contribuições de diversos autores (GIL, 1999) e por essa pesquisa ter sido 
elaborada tendo como base em livros e artigos (VERGANA, 2000). E, por fim, sua natureza qualitativa é justificativa porque tem-se como objetivo identificar as percepções e opiniões dos professores tutores em relação às ferramentas educacionais baseadas em M-learning (GIL, 2002), e quantitativa, pela utilização de dados estruturados (MATAR, 2001).

Foi realizado no Núcleo Integrado de Educação a Distância SESI/SENAI do Departamento Regional SESI/SENAI de Goiás. No período de agosto de 2017 a janeiro de 2018. Foi aplicado um questionário com perguntas fechadas e abertas, com vinte seis questões utilizando o Google forms aos professores tutores do NIEaD. O link do questionário foi enviado por meio do aplicativo watssap, essa ação se deu dessa forma, para que fossemos condizentes com nossa pesquisa que discorre sobre aspectos relacionados ao uso ferramentas educacionais por meio de dispositivos móveis.

\section{DISCUSSÕES E RESULTADOS}

Ao analisar diversos documentos institucionais foi possível identificar as principais ferramentas educacionais baseadas em M-learning utilizadas na EAD do SENAI Goiás. São elas: SENAI APP, Estante Virtual, Realidade Aumentada e Simuladores Virtuais.

\subsection{SENAI APP}

O SENAI APP é um aplicativo para conectar estudantes e docentes em torno de situações desafiadoras e significativas. $\mathrm{O}$ aplicativo permite que os docentes possam criar atividades baseadas em situações de aprendizagem e enviar essas atividades para os dispositivos móveis dos estudantes, para que esses possam resolvê-las utilizando-se dos recursos disponíveis nos dispositivos móveis como fotos, vídeos ou recursos de áudio. $\mathrm{O}$ estudante tem como, por exemplo, montar um diagrama elétrico, tirar uma foto e enviá-la ao professor para avaliação. Também, pelo aplicativo, o professor dá retorno sobre o desempenho dos alunos e, se isso for feito com a turma inteira, os alunos recebem medalhas e aparecem num ranking. (CNI, 2016).

\subsection{Estante Virtual}

É um aplicativo independente, que permite que os alunos tenham acesso aos livros dos cursos de Habilitação Técnica e de Qualificação Profissional do SENAI de forma digital. Esse acesso pode ser realizado através de dispositivos móveis, ou até mesmo por um computador desktop. 


\subsection{Realidade Aumentada}

A CNI (2016) diz que

Com o Aplicativo de Realidade Aumentada, os alunos utilizam a câmera do celular ou do tablet para reconhecimento em 3D de imagens dos livros didáticos do SENAI. Além disso, o app permite aos estudantes acessarem simuladores e vídeos, pelos quais os objetos impressos ganham movimento, imagem, som e interação.

Permite, com isso que uma interação do aluno com o conteúdo. Assim, possibilita que os livros didáticos possam ser ampliados com novos objetos de aprendizagem e com outros tipos de recursos multimídia adicionais.

\subsection{Simuladores Virtuais}

E por último trazemos a ferramenta educacional simulador virtual, que de acordo com o CNI (2014) são softwares capazes de reproduzirem de forma aproximada o comportamento e situação de algum maquinário ou atividade de certas profissões. Diante disso, os simuladores permitem que os alunos vivenciem situações prática de manuseio de equipamentos e maquinas, sem estar, de fato, em um ambiente físico com esses equipamentos.

\subsection{Aplicação do questionário}

No questionário aplicado junto aos professores tutores obtivemos dezoito respondentes, totalizando $100 \%$ de participação.

\subsubsection{Perfil professor tutor}

Quanto ao perfil dos professores tutores, temos que: $56,4 \%$ são do sexo feminino, $55,6 \%$ possuem pós-graduação latu senso, $55,6 \%$ sua área de formação se enquadra dentro da grande área ciências exatas e da terra, em especial, nos cursos de engenharia, 55,5\% tem idade entre 30 e 40 anos, 50\% possuem habilidade avançada em informática, $55,5 \%$ já foram docentes de quatro ou mais instituições, $77,8 \%$ são docentes a mais de 5 anos. Com relação à atuação no SENAI: 66,7\% atuam em cursos técnicos, $77,8 \%$ fazem tutoria de 6 a 10 turmas e 73,9\% acompanham de 100 a 200 alunos, $61,1 \%$ tem de 3 a 4 anos que trabalham no SENAI.

\subsubsection{Percepções Professores Tutores}


Em relação às percepções dos professores tutores, foram observados três aspectos, em relação ao conceito de M-learning, ao uso de ferramentas educacionais, a avaliação das principais ferramentas educacionais e a aplicabilidade de ferramentas educacionais baseadas em M-learning no processo de ensino-aprendizagem. Sobre o conceito de Mlearning, $66,7 \%$ respondeu que sabem o que significa. No segundo aspecto, sobre o uso de ferramentas educacionais, detectou-se que $77,8 \%$ utilizam a estante virtual. E na tabela 1 expõe outras ferramentas educacionais baseadas em M-learning utilizadas pelos professores tutores.

Tabela 1: Outras Ferramentas Educacionais Utilizadas

\begin{tabular}{|l|l|}
\hline Fundacentro & 1 \\
\hline M.T.E & 1 \\
\hline Kahoot & 1 \\
\hline Mob NR & 2 \\
\hline Simuladores (portal MEC) & 3 \\
\hline Watssap & 2 \\
\hline
\end{tabular}

Fonte: Elaborado por DE SÁ FILHO, Paulo (2017)

Sobre a avaliação das principais ferramentas educacionais, terceiro aspecto, os professores tutores fizeram as seguintes avaliações, 50\% consideram o SENAI regular ou bom e 33,3\% não o utilizam, acerca da Estante Virtual $77,7 \%$ classificaram como bom ou muito bom e todos utilizam, 44,4\% não utilizam os Simuladores Virtuais e 38,9\% consideram bom ou muito bom, e em relação à Realidade Aumentada 61,1\% avaliaram como bom ou muito bom e $22,2 \%$ não utilizam. E na tabela 1 , são apresentados os pontos positivos e pontos de melhoria em relação às ferramentas educacionais apontadas pelos professores tutores.

Tabela 2: Pontos positivos e de melhoria das Ferramentas Educacionais 


\begin{tabular}{|c|c|}
\hline \multicolumn{2}{|c|}{ Pontos Positos } \\
\hline Acessibilidade aos conteúdos a qualquer hora e em qualquer lugar & 8 \\
\hline Auxilia no estudo facilitando o processo de ensino-aprendizagem & 4 \\
\hline Traz inovação aos cursos & 3 \\
\hline Intergram teoria e a prática & 2 \\
\hline Pontos de Melhoria & 8 \\
\hline Desatualização das ferramentas & 3 \\
\hline Falta de opção para download dos livros & 5 \\
\hline Dificuldade no acesso a ferramenta & 2 \\
\hline Pouco insentivo no uso das ferramentas
\end{tabular}

Fonte: Elaborado por DE SÁ FILHO, Paulo (2017)

E, por último, a respeito a aplicabilidade de ferramentas educacionais baseadas em Mlearning no processo de ensino-aprendizagem, 17 dos 18 respondentes mostram-se favoráveis, como evidenciado no gráfico 1.

Gráfico 1: Viabilidade das Ferramentas Educacionais baseadas em M-learning no Processo de Ensino-Aprendizagem

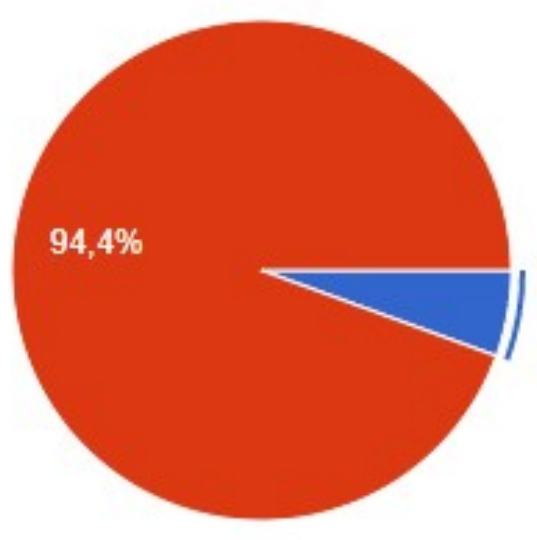

Inviáveis, pois não contribuem no processo de ensino-aprendizagem dos alunos

Viáveis, pois contribuem no no processo de ensino-aprendizagem dos alunos

Fonte: Elaborado por DE SÁ FILHO, Paulo (2017)

Mediante os resultados obtidos, é importante formatar propostas de intervenção, que tenham como base três aspectos: realizar formação de professores acerca do $\mathrm{M}$ learning; publicizar ferramentas educacionais que podem ser utilizadas por meio de dispositivos móveis no processo de ensino-aprendizagem; estruturar experiências educacionais que proponham o uso de ferramentas educacionais baseadas em $\mathrm{m}$ learning no processo de ensino-aprendizagem. 


\section{CONSIDERAÇÕES FINAIS}

Esta pesquisa proporcionou conhecer as principais ferramentas educacionais baseadas em M-learning utilizadas nos cursos a distância do SENAI Goiás, bem como as percepções dos professores tutores dessa instituição de ensino acerca dessas ferramentas e da aprendizagem móvel. Tais percepções se demonstram favoráveis, seguindo os resultados da maioria das pesquisas levantadas para suporte na elaboração do presente estudo. Conforme Crawford e Vahey 2002 e Rodrigues 2007 (apud Bottentuit Junior, 2012), apresentando resultado de uma pesquisa com cento e duas Instituições de Ensino Americanas, diz que 90\% dos professores acreditam que os dispositivos móveis podem ter um impacto positivo na aprendizagem dos alunos.

Contudo, há de se ressaltar que, apesar dessa aceitação majoritária dos docentes, grande parte deles utilizarem as ferramentas educacionais baseadas em M-learning, não conhecem o seu conceito, assim, viabilizando a elaboração de estudos e propostas que tenham como objetivo difundir e propagar o uso dessas ferramentas e capacitar os docentes para utilização dos dispositivos móveis como parte do processo de ensinoaprendizagem, evidenciando o conceito de M-learning. Pois, como destaca Moran (2013), o digital não será um acessório complementar, mas um espaço de aprendizagem tão importante como o da sala de aula. Sobre esse cenário de crescente utilização dos dispositivos móveis no processo de ensino-aprendizagem é de extrema importância ressaltar que tais ações só vão ser realmente eficazes e eficientes se propiciarem uma educação que permita a emancipação dos indivíduos a tal ponto que eles realmente sejam livres em suas escolhas e na construção de sua história.

\section{REFERÊNCIAS}

BOTTENTUIT JUNIOR. João Batista. Do Computador ao Tablet: Vantagens Pedagógicas na Utilização de Dispositivos Móveis na Educação. Disponível em:< http://www.latec.ufrj.br/revistas/index.php?journal=educaonline>. Acesso em: 13 out. 2017.

CERVO, A. L.; BERVIAN, P. A. Metodologia científica. São Paulo: Prentice Hall, 2002.

CNI. Confederação Nacional da Industria. Alunos do SENAI usam aplicativos de realidade aumentada para aprender de forma divertida e inovadora. Disponível em:< http://www.portaldaindustria.com.br/agenciacni/noticias/2016/08/alunos-do-senai-usamaplicativos-de-realidade-aumentada-para-aprender-de-forma-divertida-e-inovadora/> Acesso em: 20 set. 2017. 
CNI. Confederação Nacional da Industria. Aplicativos para smartphones e tablets complementam aulas de cursos técnicos do SENAI. Disponível em: $<$ http://www.port aldaindustria.com.br/agenciacni/noticias/2016/01/aplicativos-para-smartphones-e-tabletscomplementam-aulas-de-cursos-tecnicos-do-senai/> Acesso em: 20 set. 2017.

CNI. Confederação Nacional da Industria. Com ambiente virtual e simuladores 3D, exposição do SENAI apresenta futuro das tecnologias de aprendizagem. Disponível em:<http://www.portaldaindustria.com.br/agenciacni/noticias/2014/05/com-ambiente-virt ual-e-simuladores-3d-exposicao-do-senai-apresenta-futuro-das-tecnologias-deaprendizagem/> Acesso em: 20 set. 2017.

IBGE. Instituto Brasileiro de Geografia e Estatistica. Acesso à internet e à televisão e posse de telefone móvel celular para uso pessoal. Coordenação de Trabalho e Rendimento. - Rio de Janeiro : IBGE, 2016.

FERREIRA, J. B. et al. A disseminação da aprendizagem com mobilidade (mlearning). Pesquisa Brasileira em Ciência da Informação e Biblioteconomia, v. 8, n. 1, 2013.

MORAN. José. Tablets para todos conseguirão mudar a escola? Disponível em:. Acesso em: 20 set 2017.

MOSCARDINI.Ticiana Nunes, MONTICELLI. Jefferson Marlon, VELLOSO. Marcia. Nível de utilização do M-learning (aprendizagem com mobilidade) por alunos de graduação: uma pesquisa survey. XXXVII Encontro da ANPAD, Rio de Janeiro, 2013.

PRENSKY. Marc. Nativos Digitais, Imigrantes Digitais. Disponível em: $:$ http://poetada smoreninhas.pbworks.com/w/file/fetch/60222961/Prensky\%20-\%20Imigrantes\%20e\%20 nativos\%20digitais.pdf>. Acesso em: $18 \mathrm{dez} 2017$.

SANTOS. Marisilvia dos, SCARABOTTO. Suelen do Carmo dos Anjos, MATOS. Elizete Lucia Moreira. Imigrantes e nativos digitais: um dilema ou desafio na educação? Disponível em:< http://educere.bruc.com.br/CD2011/pdf/5409_3781.pdf>. Acesso em: $18 \mathrm{dez} 2017$.

SEEGGER. Vania, CANES. Suzy Elisabeth, GARCIA. Carlos Alberto Xavier. Estratégias tecnológicas na prática pedagógica. Disponível em: <https://periodicos.ufsm.br/remoa/article/viewFile/6196/3695>. Acesso em: 25 out. 2017. 